Utah State University

DigitalCommons@USU

1974

\title{
The development of Hypoxylon canker of Populus tremuloides: role of ascospores, conidia, and toxins
}

\author{
D.K. Bagga \\ E.B. Smalley
}

Follow this and additional works at: https://digitalcommons.usu.edu/aspen_bib

Part of the Forest Sciences Commons

\section{Recommended Citation}

D.K. Bagga, E.B. Smalley. 1974. The development of Hypoxylon canker of Populus tremuoides: role of ascospores. conidia. and toxins. Phytopathology. (64) 5: 654-658

This Article is brought to you for free and open access by the Aspen Research at DigitalCommons@USU. It has been accepted for inclusion in Aspen Bibliography by an authorized administrator of DigitalCommons@USU. For more information, please contact

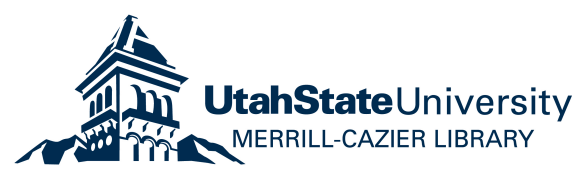




\section{The Development of Hypoxylon Canker of Populus tremuloides: Role of Ascospores, Conidia, and Toxins}

Davinderjit K. Bagga and Eugene B. Smalley

Former Research Assistant and Professor, respectively, Department of Plant Pathology, University of Wisconsin, Madison 53706.

Research supported by the College of Agricultural and Life Sciences, University of Wisconsin. Accepted for publication 26 November 1973.

\section{ABSTRACT}

Water-soluble, heat-resistant materials produced in culture by Hypoxylon pruinatum caused extensive bark necrosis when applied to unwounded quaking aspen (Populus tremuloides) stems. Wound inoculations with ascospores resulted in running cankers only when combined with topical applications of these phytotoxic culture filtrates.

Phytopathology 64:654-658. 
Ascospores of Hypoxylon pruinatum (Klot.) Cke. appear to constitute the major inoculum for spread of the fungus in nature (3). Gruenhagen (6) found air-borne ascospores $4.6 \mathrm{~m}$ ( $15 \mathrm{ft}$ ) from the nearest canker from mid-April through October. He never observed spore discharge when the mean temp was below $7.2 \mathrm{C}(45 \mathrm{~F})$. Wood and French (12), however, reported that ascospore discharge occurred throughout the year following precipitation, either rain or snow, even when the ambient temp was below $0 \mathrm{C}$. Anderson and French (1) found that ascospores germinated in sapwood of naturally occurring aspen (Populus tremuloides Mich.), but germination never exceeded $7 \%$. In most artificial inoculation studies, however, only limited infection by ascospores has been obtained $(4,6,11)$. Bagga and Smalley (2) recently described conditions for routine production of large cankers in trees by inoculating wounds with mycelium.

The role that conidia play in the natural spread of the disease is not clear. Berbee and Rogers (3), however, suggested that conidia probably were not involved in vegetative propagation of the fungus, but function in nature only as spermatia.

The present investigations include studies on the role of ascospores, conidia and toxin in disease development.

MATERIALS AND METHODS.-Aspen plants used in greenhouse and growth chamber studies were derived from root cuttings taken from naturally cankered trees at the University of Wisconsin Arboretum at Madison. Plant materials and techniques for growing rooted aspen cuttings have been described previously (2). Greenhouse temp were adjusted for $21 \mathrm{C}$ night and $24 \mathrm{C}$ day with a photoperiod of $16 \mathrm{~h}$ maintained with supplemental incandescent illumination. Growth chambers were adjusted to the prescribed temp with a photoperiod of $16 \mathrm{~h}$ under 21,520 lux of 1/3 "Gro-lux" and $2 / 3$ "Cool-white" fluorescent lights manufactured by Sylvania Co., Mass.

Ascospores were obtained from perithecial stromata collected from naturally infected aspens. After being soaked in water for $2-3 \mathrm{~h}$, the stromata were affixed to the top of a sterile petri dish with Vaseline, and ascospore discharge began after $24 \mathrm{~h}$ with release continuing for 3-4 days. The plates were covered with moist cheesecloth during ascospore discharge to prevent dehydration. Ascospores were stored at $4 \mathrm{C}$ in sterile, tightly capped glass vials. Pure single ascospore cultures were obtained by spreading a dilute suspension of ascospores on streptomycin sulfate $(50 \mathrm{ppm})$ malt agar. After $48 \mathrm{~h}$ of incubation at room temp, the germinated single ascospores were transferred aseptically to malt agar tube slants.

Conidial suspensions were prepared either from naturally infected aspen cankers or from pure "conidial type" cultures. The suspension was shaken and centrifuged at $500 \mathrm{~g}$ for $10 \mathrm{~min}$ to remove contaminating hyphal fragments. The supernatant was then passed through a double layer of Reeve-Angel No. 202 filter paper. Microscopic examination of these suspensions revealed only conidia.

Stock cultures of fungus were maintained at room temp on malt agar slants and were transferred every 2 or $3 \mathrm{wk}$. Cultures for short-term storage were maintained at $4 \mathrm{C}$. Slant cultures were preserved for longer periods under sterile mineral oil.
In most of the inoculations, unless otherwise specified, plant stems were surface-disinfected with $70 \%$ ethyl alcohol and wounded $17 \mathrm{~cm}$ above the soil line. Wounds consisted of $7.0-\mathrm{mm}$ tangential cuts which exposed the xylem. Mycelial blocks about $5 \mathrm{~mm}$ in diam cut from 2wk-old malt agar cultures were placed between the bark and wood and the wounds were covered with sterile cheesecloth and Sealtex Latex Bandage* (Sealtex Co., Chicago, III.).

The degree of disease development on inoculated plants was expressed as the number of plants developing cankers and the lengths of the cankers developed after a specified period. Presence of $H$. pruinatum in the induced cankers was confirmed by reisolation.

RESULTS.-To determine the reasons for the failure of ascospores and conidia of $\mathrm{H}$. pruinatum to regularly induce cankers in wounds under artificial conditions, fifty 70-cm-tall aspens grown in the greenhouse were wounded and the wounds treated in one of the following ways: (i) dry masses of ascospores dusted on the exposed wood, (ii) masses of ascospores mixed with $2 \%$ malt agar placed in the wounds, (iii) germinated ascospores in $2 \%$ malt agar placed in the wounds, (iv) sterile $2 \%$ malt agar placed in the wound, or (v) untreated. To induce the necessary water stress (2), all the plants were watered every 4 th day. None of the plants developed cankers even after 4 months of incubation.

In a second study, 60 plants were inoculated by injection of one of the following in wounds $2 \mathrm{~mm}$ in diam drilled into the leaf axils: (i) ascospores in water; (ii) ascospores in $1 \%$ glucose; (iii) ascospores in $2 \%$ malt extract; (iv) conidia in water; (v) conidia in $1 \%$ glucose; or (vi) conidia in $2 \%$ malt extract. Spore concns in all cases were approximately $10^{6}$ spores $/ \mathrm{ml}$. Similar wounds on 30 other plants were injected with water, $1 \%$ glucose, or $2 \%$ malt extract. Treatment sites were then covered with moistened cotton and sealed with masking tape. All plants were watered to field capacity every 4th day (2).

TABLE I. Influence of the type of inoculum on infection and canker development in greenhouse-grown aspens under water stress'

\begin{tabular}{lc}
\hline \hline \multicolumn{1}{c}{ Inoculum type } & $\begin{array}{c}\text { Ratio of } \\
\text { plants infected } \\
\text { to total inoculated }\end{array}$ \\
\hline Water & $0 / 10$ \\
Conidia in water & $5 / 10$ \\
Ascospores in water & $5 / 10$ \\
$1 \%$ Glucose & $0 / 10$ \\
Conidia in 1\% glucose & $4 / 10$ \\
Ascospores in $1 \%$ glucose & $2 / 10$ \\
$2 \%$ Malt extract & $0 / 10$ \\
Conidia in $2 \%$ malt extract & $5 / 10$ \\
Ascospores in $2 \%$ malt extract & $3 / 10$ \\
\hline
\end{tabular}

'Suspensions were injected into 2-mm diam holes drilled into the leaf axils of plants watered every 4 th day.

Infection was defined as browning of the xylem a distance beyond the point of inoculation, and by reisolation of the pathogen from these discolored areas. No running cankers developed from any of the treatments. 
TABLE 2. Influence of extracts from Hypoxylon pruinatum cultures on canker development on greenhouse-grown aspen after inoculation with ascospores ${ }^{2}$

\begin{tabular}{|c|c|c|c|}
\hline \multirow[b]{2}{*}{ Inoculation site } & \multirow[b]{2}{*}{ Wound covering } & \multicolumn{2}{|c|}{ Cankered plants } \\
\hline & & Inoculated & Control \\
\hline Exposed wood & Moistened cotton & $0 / 10$ & $0 / 10$ \\
\hline $\begin{array}{l}\text { Exposed wood } \\
\text { (wounds re-opened daily for } 3 \text { days) }\end{array}$ & Moistened cotton & $1 / 10$ & $0 / 10$ \\
\hline Exposed wood & Blended culture in collodion bag ${ }^{b}$ & $5 / 10$ & $0 / 10$ \\
\hline Exposed wood & $\begin{array}{l}\text { Cotton moistened with cell-free } \\
\text { fungal extract }\end{array}$ & $10 / 10$ & $0 / 10$ \\
\hline Exposed wood & $\begin{array}{l}\text { Cotton moistened with autoclaved } \\
\text { fungal extraet }\end{array}$ & $10 / 10$ & $0 / 10$ \\
\hline $\begin{array}{l}\text { Leaf axil (two/plant) } \\
\text { (Inoculum introduced with hypodermic } \\
\text { syringe) }\end{array}$ & Moistened cotton & $0 / 10$ & $0 / 10$ \\
\hline $\begin{array}{l}\text { Leaf axil (two/plant) } \\
\text { (Inoculum injected with hypodermic syringe) }\end{array}$ & $\begin{array}{l}\text { Cotton moistened with cell-free } \\
\text { fungal extract }\end{array}$ & $10 / 10$ & $0 / 10$ \\
\hline
\end{tabular}

No running cankers developed following injection of any of the various spore suspensions (Table 1). Half of the plants inoculated with the spores in water suspension, however, became infected and browning of wood without canker development was still evident after 3 mo. Fewer plants became infected after inoculation with the glucose and malt extract ascospore suspensions, although the pathogen was readily reisolated from the infected wood up to $42 \mathrm{~mm}$ beyond the site of inoculation. Only slight discoloration at the site of injection developed in the control plants, and these sites were sterile.

To further clarify the uncertain role of ascospores as natural inoculum, each of 70 greenhouse-grown 4-mo-old aspens was inoculated in one of several ways. Fifty plants were wound-inoculated by dusting a dry mass of ascospores on the exposed wood of each plant. The dry spores were transferred on a small camel's-hair brush. The wounds on 20 of these plants were covered with sterile cotton moistened in sterile distilled water and half of these plants were rewounded every day for 3 days. The inoculated wounds of the remaining 30 plants were either covered with cotton moistened with a cell-free aqueous prepared extract from 14-day malt agar cultures of $H$. pruinatum, with cotton moistened with the autoclaved fungal extract, or with a collodion bag containing a blended culture of the fungus. The fungal extracts were prepared by blending mycelium removed from 14-day malt agar cultures of the fungus. The last 20 plants were inoculated by hypodermically injecting ascospores suspended in either water or cell-free fungal extract into holes drilled into leaf axils (two inoculated axils/plant). The wounds inoculated with ascospores in water were covered with moist cotton, while wounds inoculated with ascospores in fungal extract were covered with cotton moistened with fungal extract. Another 70 wounded, noninoculated plants, 10 plants/treatment, were similarly treated and served as controls. The wound sites of all plants were then sealed with latex bandage and all plants were watered every 3 days.
All ascospore-inoculated plants developed running cankers when the ascospores were suspended in cell-free fungal extract and injected into leaf axils, or when cotton moistened with the extract covered the ascosporeinoculated wounds (Table 2). Half of the plants also developed cankers when the ascospore-inoculated wounds were surrounded with collodion bags containing an active blended culture of $H$. pruinatum. Only $10 \%$ of the inoculated plants in which wounds were reopened every $24 \mathrm{~h}$ for 3 days developed cankers. The other treatments were not successful.

In various experiments concerned with the mode of entry of $H$. pruinatum, it was observed that mycelial surface inoculations of nonwounded tissues caused severe blackening of the bark. During the experiment, the plants had been watered every fourth day, and 3 to 4 wk after inoculation, small vertical cracks appeared in these blackened areas. Dissection indicated that blackening did not extend into the wood. Attempts to isolate the pathogen from such affected areas failed. The blackening was overgrown after $2 \mathrm{mo}$, and the affected areas turned brown but retained their corroded appearance (Fig. 1).

Studies were initiated to discover whether the living fungus was necessary to produce this blackening. Colonies of $\boldsymbol{H}$. pruinatum grown on malt agar for $2 \mathrm{wk}$ were killed by exposure to propylene oxide vapors for 48 h. The fungus was then transferred to malt agar to detect any remaining living mycelial fragments. Five plants, 65 $\mathrm{cm}$ tall in $10.1-\mathrm{cm}$ (4-inch) diam pots were treated on the unwounded bark surface with sterile malt agar; five similar plants were inoculated on the nonwounded surface with a plug from an actively growing colony of the fungus; five other plants were inoculated with a plug from the propylene oxide-treated colony. All the inoculations were covered with waxed paper and sealed with latex bandage.

All treated areas of the stems blackened after $2 \mathrm{wk}$ except in those treated with sterile malt agar. No running, 


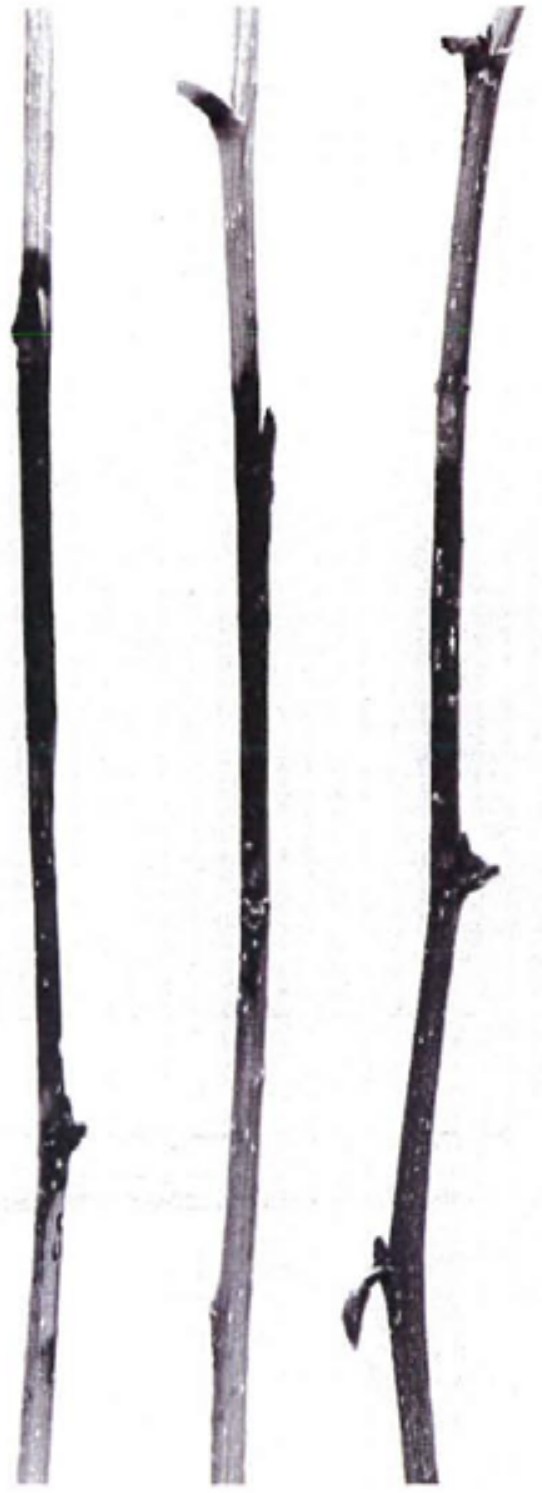

Fig. I. Necrogenic effect caused by autoclaved mycelium of IJpoxylon pruinatum on the nonwounded aspen stem.

fungus-invaded cankers developed from any of the treatments.

DISCUSSION - Ascospores presumably are the major inoculum for natural infection, although Hubbes and d'Astous (8) have suggested that conidia may be important in the propagation of the pathogen. In our investigations, conidial suspensions injected into leaf axils consistently resulted in greater numbers of infected sites than similar plants injected with ascospore suspensions. Although neither treatment produced running cankers, the results suggested the possible importance of conidia in natural pathogenesis.

Repeated efforts by others to obtain infection with ascospores have been poor or have failed $(4,9,10)$ (T. Sasaki, unpublished manuscript on file at the Plant Pathology Department, Univ. of Wisconsin, Madison).
Various reasons are suggested for failure to produce infection with ascospores, but the factors involved remain unknown. Wood and French (12) suggested that the failure could be due to the inhibition of ascospore germination caused by the bacterial contaminations that are associated with ascospores in perithecia. However, Hubbes and d'Astous (8) questioned that bacterial contamination is the main factor for the inhibition of ascospore germination. French and Oshima (5) suggested that ascospore infection takes place at branch axils where the green tissue inhibitory to ascospore germination is minimal or lacking. In our studies, ascospore suspensions injected into leaf axils failed to cause cankers even in plants under water stress. Berbee and Rogers (3) failed to get infection with ascospores even when spores were placed in contact with the tissues beneath the inhibitory phelloderm. They suggested that failure could have been due to rapid callus formation over the wounds during the 24-28 h required for ascospore germination. Hubbes (7) reported the presence of some toxic substances produced in culture by $H$. pruinatum, which prevented the callus formation over a bark wound. In the present studies, cankers developed in all plants inoculated with ascospores when cell-free fungal extracts from cultures were applied topically over the inoculated wounds. A metabolite from the culture filtrate was apparently required for the production of running cankers with ascospore inoculum. This product was heat-resistant and water-soluble. If present on or produced by ascospores, it was not present in sufficient quantity at the inoculum concn used in these experiments to induce cankers. Possibly in nature very large clumps of ascospores, such as might possibly be carried by insects, would contain high enough concns of this metabolite for canker developments.

\section{LITERATURE CITED}

1. ANDERSON, D. L.. and D. W. FRENCH. 1972. Germination of ascospores of Hypoxylon mammatum in living aspen. Can. J. Bot. 50:1973-1974.

2. BAGGA, D. K., and E. B. SMALLEY. 1969. Factors affecting canker development on Populus tremuloides artificially inoeulated with Hypoxylon pruinatum.Can. J. Bot. 47:907-914.

3. BERBEE, J. G., and J. D. ROGERS. 1964. Life cycle and host range of Hypoxylon pruinatum and its pathogenesis on poplars. Phytopathology 54:257-261.

4. BIER, J. E. 1940. Studies in forest pathology. III. Hypoxylon canker of poplar. Can. Dep. Agric. Tech. Bull. 27. 40 p.

5. FRENCH, D. W., and N. OSHIMA. 1959. Host bark characteristics and infection by Hypoxylon pruinatum (Klot.) Cke. For, Sci, 5:255-258.

6. GRUENHAGEN, R. H. 1945. Hypoxylon pruinatum and its pathogenesis on poplar. Phytopathology 35:72-89.

7. HUBBES, M. 1964. New facts on host-parasite relationships in Hypoxylon canker of aspen. Can. J. Bot. 42:1489-1494.

8. HUBBES, M., and R. d'ASTOUS. 1967. Faetors affecting the germination of spores of Hypoxylon pruinatum. Can. J. Bot. 45:1145-1153.

9. ROGERS, J. D. 1963. Hypoxylon canker of aspen. I. Sereening for disease resistance. II. Developmental morphology and cytology of Hypoxylon pruinatum. Ph.D. Thesis, Univ. Wisconsin, Madison. 140 p. 
10. SHEA, K. R. 1954. Poplat improvement in Wisconsin. I. Regulated pollination. seed storage and control of damping-off. II. Hypoxylon canker of aspen. Ph.D. Thesis, Univ. Wisconsin, Madison. 137 p.

1I. SHEA, K. R., and J. E. KUNTZ. 1956. Effective inoculation of aspen with Hypoxylon pruinatum. Phytopathology 46:26 (Abstr.).

12. WOOD, F. A., and D. W. FRENCH. 1962. Ejection of ascospores by Hypoxylon pruinatum during the winter in Minnesota. Phytopathology 52:33 (Abstr.). 